Eixo Temático: Processos de Ensino-Aprendizagem

\title{
ET-06-003 \\ RELATO DE EXPERIÊNCIA DO CIRCUITO DE OFICINAS DE ATIVIDADES PRÁTICAS NO ENSINO CIÊNCIAS
}

Magnólia Silva Queiroz, Fabiano Hebert da Conceição², Grasiele Santana Santos², Marilize Ferreira Santos², Suzana de Azevedo Alves²

${ }^{1}$ Docente da Universidade do Estado da Bahia (UNEB/Campus II/ Alagoinhas/BA). ${ }^{2}$ Estudante de Licenciatura em Ciências Biológicas da Universidade do Estado da Bahia (UNEB/Campus II/ Alagoinhas/BA).

http://dx.doi.org/10.21472/congrebio2016.et-06-003

\section{RESUMO}

Este artigo apresenta o relato de experiências de um circuito de oficinas realizado por graduandos em biologia sobre atividades práticas no ensino de ciências. O objetivo desse trabalho foi mostrar a possibilidade de aplicar as atividades com materiais de baixo custo, além de promover discussão e reflexão do conteúdo envolvido, como a densidade. Como resultado alcançado, pode-se afirmar que o circuito de oficinas no ensino de ciências é importante porque apresenta grande potencial para o ensino e a discussão acerca dela deve ser feita no ambiente acadêmico para que se efetive no contexto escolar.

Palavras-chave: Ensino de ciências; Oficina; Atividade prática.

\section{INTRODUÇÃO}

O relato que segue é produto da experiência de oficinas de quatro estudantes de Licenciatura em Biologia que se depararam com o desafio de executar um circuito de oficinas de atividades práticas no ensino de ciências com materiais de baixo custo, abordando conteúdos como pressão atmosférica e densidade.

A necessidade da realização dessas oficinas partiu dos próprios acadêmicos da referida licenciatura durante as discussões de um componente curricular de cunho pedagógico. Tomando como base o entendimento de que atividades práticas não são exclusivas as realizadas em laboratórios, e levando em consideração que em muitas escolas da rede municipal e estadual de ensino básico baiano não têm estrutura de laboratório de ensino de ciências. Assim, diante da atual realidade, os acadêmicos entenderam que para se construir conhecimento a sala de aula também se constitui em um laboratório, ou seja, em local para fazer ciência e dessa forma pesquisaram, elaboraram atividades e demonstraram as práticas no pátio da universidade.

A realização de oficinas de atividades práticas no ensino de ciências é importante para o processo de formação inicial de professores, em que o graduando deverá mobilizar os conhecimentos científicos construídos nos componentes específicos e refletir sobre a sua prática pedagógica para que esta seja significativa. Neste sentido, a execução de oficinas surge como um processo fundamental na formação do graduando, uma vez que este vivencia novas experiências e experimenta na prática como ocorre o processo de ensinar.

O ambiente acadêmico é o local mais adequado para o desenvolvimento de ações voltadas à realização de oficinas, pois as ações implementadas sempre oferecem oportunidades para se refletir sobre as atividades realizadas, o que contribui para o conhecimento e crescimento de todos envolvidos no processo, trazendo aplicabilidade da teoria de forma contextualizada, além de permitir a interação da comunidade acadêmica neste processo. 
Sendo o contexto da pesquisa sobre atividades práticas no ensino de ciências, estudos mostram que nas escolas, as atividades práticas ainda são pouco frequentes, embora permaneça a crença dos professores de que, por meio delas, pode se transformar o ensino de ciências.

Cappechi e Carvalho (2006) ressaltam que as aulas do tipo "receita de bolo", são como forma de confirmar determinado conhecimento científico, obrigando os estudantes a verificar a "veracidade" de determinadas teorias em vez de investigá-las.

Assim, relatar essas experiências favorecerá para refletir sobre o processo de ensinar a partir do circuito de oficinas vivenciadas, além de possibilitar o desenvolvimento de postura crítica. Segundo Maldanner (2007), o ensino de ciências se mantém de modo tradicional em muitas escolas, o que gera insatisfação por parte dos alunos e, em consequência, também dos professores.

\section{METODOLOGIA}

O circuito de oficinas aconteceu no pátio da Universidade do Estado da Bahia - UNEB, Campus II, Alagoinhas-BA e se constituiu de dois momentos: o primeiro momento os estudantes de biologia demonstraram as atividades práticas experimentais sobre densidade. No segundo momento, os estudantes que participaram do primeiro momento executaram práticas experimentais a partir de roteiros sobre a mesa.

Ao demonstrar o experimento com uvas passas, os estudantes de biologia relacionaram conhecimentos sobre a densidade relativa dos corpos com o sobe e desce das uvas, quando estas foram colocadas dentro de um copo transparente contendo 3/4 de refrigerante gaseificado de limão que foi aberto no momento do experimento. No experimento teste, as uvas passas foram colocadas em água da torneira. A partir disso, surgiram os seguintes questionamentos entre os estudantes: Qual propriedade da matéria está relacionada ao fenômeno de subir e descer das uvas passas? Até quando esse fenômeno das passas se repetirá dentro líquido? As bolhas dentro do refrigerante são de qual gás? Por que algumas uvas passas, apesar de estarem com muitas bolhas de gás não flutuam e ficam no fundo do copo?

No segundo momento, os estudantes executaram as atividades práticas experimentais a partir de roteiros dispostos em cima da mesa e propuseram uma explicação a partir da observação do comportamento das uvas passas a partir da mistura de substâncias, água e efervescente. Inicialmente, $3 / 4$ de água em um copo mais uvas passas, e em seguida acrescentaram o efervescente.

A partir destes procedimentos, neste trabalho está uma discussão qualitativa que fundamentada na perspectiva de atividades práticas experimentais a qual se acredita que favorece a melhoria do ensino de ciências. O ensino adequado de ciências estimula o raciocínio lógico e a curiosidade, ajuda a formar cidadãos mais aptos a enfrentar os desafios da sociedade contemporânea (Academia Brasileira de Ciências, 2008).

\section{RESULTADOS E DISCUSSÃO}

O circuito de oficinas ocorreu durante uma manhã, mas antes houve uma preparação ainda na sala de aula, durante as aulas do componente curricular Prática Pedagógica IV, com leituras e reflexões sobre a docência, assim como a escolha das atividades práticas experimentais, seguido do estudo do conteúdo das práticas, teste das práticas e por fim aplicação do circuito das oficinas. Tudo aconteceu com o auxílio da professora orientadora.

As reflexões sobre a docência por se constituírem em uma das mais investigadas na área da educação, se fundamentaram nos conhecimentos necessários para o professor de ciências biológicas exercer durante a sua prática pedagógica.

A escolha da atividade prática experimental "Uvas-passas como elevador químico" ocorreu por dois motivos: É um experimento simples e possível de ser realizado em sala de aula do ensino básico com materiais do uso cotidiano; quando bem teorizados chegam a resultados interessantes. 
O estudo do conteúdo densidade por ser trabalhado no 9 ano do ensino fundamental II consistiu da leitura de dois livros didáticos de ciências e de textos complementares da internet, e resolução de questões para que fosse possível no momento da demonstração das atividades experimentais teorizar o conteúdo densidade. $\mathrm{Na}$ análise das falas dos estudantes verificou-se que a maioria dos argumentos feitos estudantes começam a falar no sentido de explicar o sobe e desce das uvas passas. Para alguns, essa questão ainda é obscura.

Os estudantes não tiveram dificuldade em dizer que os refrigerantes contêm quantidade apreciável de gás $\mathrm{CO}_{2}$ (dióxido de carbono), dissolvido no líquido sob pressão. Dessa forma, eles chegaram conclusão que as bolhas de gás formam-se na superfície da uva passa, fazendo com que a densidade do conjunto se torne maior do que a do liquido, e por isso ela sobe. Quando a passa atinge a superfície, parte das bolhas estouram e a densidade da passa torna-se então maior do que a do líquido, e elas afundam. Assim, o processo repete-se até que a quantidade de bolhas formadas não sejam suficientes para que os pedaços de passas flutuem.

A princípio, os estudantes não souberam argumentar porque algumas uvas passas afundaram, apesar de estarem com muitas bolhas de gás e não flutuavam permanecendo depositadas no fundo do copo. Com o auxílio dos estudantes de biologia foi possível entender que estas são mais densas do que o refrigerante.

No experimento teste, as uvas passas ficaram no fundo do copo.

No segundo momento, os estudantes não demostraram resistência em executar a atividade prática experimental e propuseram explicação a partir da execução das atividades experimentais. Assim, a explicação foi que após adicionar o comprimido efervescente, a densidade de algumas uvas passas diminui e dessa forma sobe e desce apresentando o mesmo comportamento que com o refrigerante.

O primeiro momento foi importante para o desenvolvimento e explicação do segundo, pois proporcionou autonomia aos estudantes durante a execução da prática experimental, além de contribuir para a explicação.

\section{CONCLUSÃO}

As experiências vivenciadas durante o circuito de oficinas foram consideradas de fundamental importância para o preparo da docência, pois desencadeou em várias reflexões sobre a prática pedagógica no ensino de ciências ensino.

A atividade prática experimental "Uvas-passas como elevador químico" para trabalhar a conteúdo densidade é importante devido à complexidade e os dados analisados neste trabalho, apresenta grande potencial para o ensino de ciências dependendo do contexto em que é inserido na sala de aula.

Sendo assim, o circuito de oficinas de práticas no ensino de ciências favoreceu para o pensar a ciência viva.

\section{REFERÊNCIAS}

ACADEMIA BRASILEIRA DE CIÊNCIAS. O Ensino de ciências e a educação básica: propostas para superar a crise. Rio de Janeiro: Academia Brasileira de Ciências, 2008.

CAPECCHI, M. C. M.; CARVALHO, A. M. P. Atividades de laboratório como instrumentos para a abordagem de aspectos da cultura científica em sala de aula. Pro-Posições, v. 17, n. 1, p. 137-152, 2006.

MALDANER, O. A. Situações de estudo no ensino médio: nova compreensão de educação básica. In: NARDI, R. (Org.). A pesquisa em Ensino de Ciências no Brasil: alguns recortes. São Paulo: Escrituras, 2007. p. 239-253. 